\title{
RACSAM
}

Rev. R. Acad. Cien. Serie A. Mat.

Vol. 101 (2), 2007, pp. 221-223

Matemática Aplicada / Applied Mathematics

Comunicación Preliminar / Preliminary Communication

\section{Plant-animal mutualistic networks: the architecture of biodiversity*}

\author{
Jordi Bascompte
}

\begin{abstract}
The mutualistic interactions between plants and the animals that pollinate them or disperse their fruits have molded the organization of Earths's biodiversity. These interactions create networks of interdependence often times involving dozens or hundreds of species. Recent research has used concepts from graph theory to characterize the architecture of these networks. Mutualistic networks are heterogeneous, nested and build upon weak and asymmetric links among species. This network architecture highly affects its robustness to perturbations such as the extinction of a species.
\end{abstract}

\section{Redes mutualistas planta-animal: la arquitectura de la biodiversidad}

Resumen. Las interacciones de beneficio mutuo entre las plantas y los animales que las polinizan o dispersan sus semillas han jugado un papel muy relevante en la generación de biodiversidad en la Tierra. Estas interacciones crean redes de interdependencia que suelen involucrar decenas o centenares de especies. Investigación reciente ha utilizado conceptos de la teoría de grafos para caracterizar la arquitectura de estas redes. Las redes mutualistas son heterogéneas, anidadas y construidas sobre interacciones débiles y asimétricas entre especies. La arquitectura de estas redes afecta en gran medida su robustez ante perturbaciones como la extinción de una especie.

The mutualistic interactions between plants and the animals that pollinate them or disperse their seeds have molded the organization of Earths's biodiversity. Plants have created new niches for insect diversification, which in turn may have increased plant diversification. The importance of these mutually beneficial interactions can be grasped by considering that more than $90 \%$ of tree species in the tropical forests need animals to complete their life cycle. Animal extinction would result in the consequent extinction of plants.

Historically, the first studies on mutualistic interactions focused on highly specialized, pairwise interactions. These examples of an almost perfect matching between the morphology of a flower and that of an insect have illustrated textbook covers since Darwin's time, but they are probably the exception rather than the norm. Mutualistic interactions may involve dozens or even hundreds of species interacting in complex ways. Progress in coevolutionary studies during the last two decades has been made by studying how small groups of species interact in a community context and how these interactions change through time and space ([9]). More recently, the physics of complex networks has provided tools and concepts to tackle entire plant-animal coevolutionary networks. These results have unambiguously concluded that mutualistic networks are highly heterogeneous (the bulk of species have a few interactions, but a few species have many more interactions than expected by chance, [6]); nested (specialists interact with proper subsets of

\footnotetext{
*This paper is based on a lecture delivered by the author, at the International Symposium Mathematics for the XXIth Century, organized in Madrid, Spain, on May 3-4, 2006, by the Ramón Areces Foundation and the Royal Academy of Sciences of Madrid, together with the Executive Committee of the International Congress of Mathematicians 2006 (ICM2006 Madrid).

Pŕresentado por Manuel de León.

Recibido: 16 de marzo de 2007. Aceptado: 10 de octubre de 2007.

Palabras clave / Keywords: Biodiversity, complex networks, ecosystems, evolution, extinctions.

Mathematics Subject Classifications: 92B05, 92D40, 94C15

(C) 2007 Real Academia de Ciencias, España.
} 
the species generalists interact with; [3]); and built upon weak and asymmetric links among species (in the few cases in which a plant, for instance, interacts strongly with an animal, the animal interacts weakly with the plant; [4]). Networks of mutualistic interactions are thus neither randomly assembled nor organized in distinct compartments arising from tight, parallel specialization. This set of papers have undercovered the geometry of biodiversity.

The above network patterns are quite universal. We see the same architecture across systems regardless of mutualism type (pollination or seed dispersal), geographic location, or species composition. To some extent, they reflect an architectonic invariant. These network patterns can be precisely described in a mathematical language, for example using truncated power-law connectivity distributions of the form:

$$
p(k) \propto k^{-\gamma} e^{-k / k_{c}},
$$

where $p(k)$ is the probability of a species having $k$ interactions and $\gamma$ is a critical exponent. The new term in relation to a scale-free distribution is $e^{-k / k_{c}}$, defining the exponential cut-off. This exponential truncation in equation (1) means that as the number of interactions reaches the critical $k_{c}$ value, the probability of finding more connected species drops faster than expected for a power-law. The data for different communities collapse to a simple scaling function when plotting the scaled cumulative distributions of links per species, $k^{-\gamma} P(k)$ vs. the scaled links per species $\left(k / k_{c}\right)([6])$. This reveals a general topological pattern pattern independent of scaling considerations, which is evident only when examining the whole network of interactions. Super-generalist species with large $k$-values are less frequent than expected from a simple scale-free, power-law distribution.

Mathematics can also illuminate consequences of network structure for community dynamics, a subject where experimental or field work is almost impossible. By using analytic models and computer simulations, it has been shown that the architecture of mutualistic networks is important in facilitating species persistence. There are two different approaches in here. The first one is topological robustness and follows the pioneering work by Albert et al. ([1]) with the Internet network. Mutualistic networks are quite robust to the random loss of species due to their high heterogeneity and nested structure, which brings a high level of cohesion quite similar to that of non-biological networks ([7]) . However, closely related species tend to play similar roles in the network. As a consequence, coextinction cascades tend to involve taxonomically related species, which results in a non-random pruning of the evolutionary tree and a more pronounced loss of evolutionary history ([8]).

The second approach to network robustness is based on the local stability analysis of steady states representing community coexistence, and numerical simulations of the dynamics of large networks. Preliminary work has shown that mutualistic networks stand for higher values of habitat destruction than random networks ([5]). Because of the above results, plant-animal mutualistic networks can be regarded as the architecture of biodiversity. These network patterns can also have important implications for the coevolution of species and for biological conservation. The implications of human-induced perturbations have to be assessed in a community context. In the context of other interaction types e.g., predator-prey, trophic interactions, it has been shown that a large Caribbean marine food-web interaction strengths between predator and their prey are combined non-randomly in trophic chains so that the likelihood of trophic cascade after species overfishing is reduced ([2]). However overfishing affects a very biased sampling of the species, mainly a few shark species which are strong interactors. Their removal can cause changes in abundance that transmit through the entire food chain and can contribute to the degradation of the coral reef ([2]). Knowing how these perturbations will propagate through the community requires a network approach ([2]), and ultimately a combination of natural history, search for invariant patterns, and analytical thinking.

Acknowledgement. I am thankful to Pedro Jordano for his comments on a previous draft and constant discussion. This work was funded by the European Heads of Research Councils, the European Science Foundation, and the EC Sixth Framework Programme through a EURYI (European Young Investigator) Award, and by the Spanish Ministry of Education and Science (Grant REN2003-04774). 


\title{
References
}

[1] Albert, R., Barabási, A-L. and Jeong, H., (2000). The Internet's Achilles Heel: Error and attack tolerance in complex networks, Nature, 406, 378-382.

[2] Bascompte, J., Melián, C. J. and Sala, E., (2005). Interaction strength combinations and the overfishing of a marine food web, Proceedings of the National Academy of Sciences USA, 100, 5443-5447

[3] Bascompte, J., Jordano, P. , Melián, C. J. and Olesen, J. M., (2003). The nested assembly of plant-animal mutualistic networks, Proceedings of the National Academy of Sciences USA, 100, 9383-9387.

[4] Bascompte, J., Jordano, P. and Olesen, J. M., (2006). Asymmetric colevolutionary networks facilitate biodiversity maintenance, Science, 312, 431-433.

[5] Fortuna, M. A. and Bascompte, J., (2006). Habitat loss and the structure of plant-animal mutualistic networks, Ecology Letters, 9, 281-286.

[6] Jordano, P., Bascompte, J. and Olesen, J. M., (2003). Invariant properties in coevolutionary networks of plantanimal interactions. Ecology Letters, 6, 69-81.

[7] Memmott, J., Waser, N. M. and Price, M. V., (2004). Tolerance of pollination networks to species extinctions, Proceedings of the Royal Society B, 271, 2605-2611.

[8] Rezende, E., Lavabre, J. E., Guimarães Jr., P. R., Jordano, P. and Bascompte, J., (2007). Non-random coextinctions in phylogenetically structured mutualistic networks. Nature, 448, 925-928.

[9] Thompson, J. N., (2005). The Geographic Mosaic of Coevolution, Chicago University Press.

\author{
Jordi Bascompte \\ Integrative Ecology Group \\ Estación Biológica de Doñana, CSIC \\ Apdo. 1056, E-41080 Sevilla, Spain \\ bascomptedebd.csic.es \\ wwW . bas compte. net
}

